\title{
Report on the XVI World Congress of Comparative Education Societies (WCCES 2016)
}

The Congress was held from 22nd to 26th August 2016 in China at the Beijing Normal University (BNU). The main theme of the Congress Dialectic of Education: Comparative Perspectives offered discussion on contemporary issues in a global, regional and local context aimed at exploring, interpreting and comparing diverse sides of educational phenomena. The dialectics of education were analysed at different stages or in various settings, including a complexity of issues concerning educational inputs and processes or outputs from different theoretical and disciplinary perspectives. It gave participants from every region of the world the opportunity to share ideas, views and methodological approaches pointing out particularities and emphasizing common trends or problems in education and educational research.

Keynote speeches focused on the main congress theme from different perspectives as follows: Ying Wang, senior professor of comparative education at BNU and the current president of the Chinese Comparative Education Society opened the way to understand the Chinese perspective. In his keynote The prospect of Chinese schools: From the Perspective of Dialectics he interpreted the development of school education and changes started in China since the reform in 1978. His speech was based on broad research evaluating the current state and conflicts in Chinese schools in the age of globalization and digitalization. In particular, he pointed out conflicts in educational aims, student engagement in learning, the different expectations that parents have and the persistence or emancipation of teachers and school principals. The main dilemma was seen in the conflict of educational standards and personalised concept of education with consequences for governance strategy, curriculum development and teaching methods, and especially for the teaching profession. Despite the real conflicts that he identified, his conclusion was fairly optimistic.

The second keynote devoted to Chinese education was presented by Ruth Hayhoe, a professor at the University of Toronto. She is deeply involved in Asian education, including several visiting professorships at Japanese, Hong Kong and Chinese universities. She has published a number of articles and books concerning Chinese education. In her keynote China in the Centre: What will it Mean for Global Education? she reflected on the restoration of universities after the Cultural Revolution and the dramatic modernization of higher education in China since the late 1970s. Furthermore, she celebrated the Chinese university culture and its influence on rapidly developing education systems in Africa and South Asia with the potential to enrich new approaches in education globally. 
Andreas Schleicher, director for Education and Skills at the OECD, guiding major programmes, such as PISA, PIAAC, TALIS and INEC, offered different perspectives on the strategic value of education. In his keynote Better Skills, Better Jobs, Better Lives: The Challenge for Connecting the Worlds of Learning and Work education was viewed as a piece of equipment needed for an effective personal link in work and social benefit in economic grow. He referred his explanation to the OECD Skills Survey (PIAAC) and pointed out the difficulties connected with poor skills or with a shortage of the advanced skills that are important for the productive use of technologies and for new ways of working. He illustrated the difficulties with evidence from international research showing that in many countries the young graduates face serious problems when looking for jobs. He showed that more education does not mean better education and that relevant skills are the right way to a better job and quality of living. He challenged the anticipation of further development in contemporary societies of learning and deeper integration between the world of work and the world of learning.

The former president of the WCCES Carlos Alberto Torres, professor at UCLA and Director of the Paolo Freire Institute, concentrated on the functions of comparative education in the global age. In his keynote The State of the Art of Comparative Education: WCCES at a Crossroad in the 21th Century he challenged the community operating in the field to a broad and complex approach going far beyond the concept of academic discipline. Comparative education today, according to Torres' view, is a relatively obscure and unconventional field acquiring a new relevance. He pointed out particularly important relations between culture and power and the dynamics of power within social movements that make education permanently full of conflicts and struggles. He confronted the state of the field with the role of the WCCES and the diverse professionalism of comparatists in the interdependent world.

The role of the WCCES was discussed during the congress differently, particularly by the highlighted panel The Future of Comparative Education performed by other past presidents. The changing role of comparative education was also the subject of thematic sessions concerning globalization, educational reforms, and the re-contextualization of world culture.

Radically reconfigured contexts, challenges and opportunities were emphasized in every thematic session showing gaps in countries and cultures or in international settings concerning education. The following aptly chosen 14 themes served as the main focuses of the congress content and discussions: Globalization and Localization, Quantity and Quality, Marketization and Public Good, Scientism and Humanism, Modernity and Tradition, Diversity and Standardization, Equity and Efficiency, Centralization and Decentralization, Autonomy and Accountability, Elite and Massive Education, Teacher-centred and Student-centred Education, Adult Education and Lifelong Learning. The last but not the least thematic session Theories and Methodologies of Comparative Education reopened discussion on the identity of the discipline and the present state of certain crisis. The rise of new theories and approaches, such as neo-institutionalism, network theories, cartographic methodol- 
ogies, multiplication of post-structural theories, in addition to debates on global and regional interpretation of common concepts, including globalization and glocalization or westernization and internationalization, reflected relevant diversities in the field.

Reflecting on the experience from the Congress the statement could be as follows: To know and compare diversities could lead to deeper understanding of education and learning in a global and local setting. To meet comparativists from the whole world, to have live discussion of theoretical and methodological questions of the research as well as real issues of educational policy and practice was a unique opportunity provided by the organizers.

To hold the Congress at Beijing Normal University was a very good choice. The University is a key institution of higher education and among the top ten universities in Mainland China. The University offers a broad range of study and research fields in arts and sciences and is well-known for teacher education and education science. It promotes broad international cooperation with a high number of universities and research centres abroad and exchange students from fifty universities particularly from the United States, the United Kingdom, Japan and South Korea. In addition, the BNU has co-established eight Confucius Institutes in North America and Western Europe.

The origins of the Faculty of Education, the main organizer of the Congress, date back to the early 20th century. Nowadays the faculty is considered a national leader in advancing teaching and research activities and innovative projects nationwide. The faculty consists of 13 academic institutes offering 5 undergraduate programmes, 28 master programmes and 16 doctoral programmes; four of these doctoral programmes are taught in English. The important centre of the faculty, the Institute of International and Comparative Education, is the oldest comparative research centre in the country and the only national centre of this kind accredited by the Ministry of Education. Since 2002 the Institute has hosted the Worldwide Forum for Comparative Education every three years. The Institute is a seat of the secretariat of the Chinese Comparative Education Society and publishes the International and Comparative Education journal.

The university and faculty staff were fully involved in academic, logistic and organizational committees. The management of the scientific and social programme of the Congress was very professional. Nearly 150 student volunteers contributed to a friendly and productive climate and the smooth running of the whole programme, including school visits and other special events. At the welcome evening the 1500 participants enjoyed Chinese traditional music, dances, calligraphy and drama performed by university students.

The double effect, scientific and cultural, contributed to the success of the congress. All that remains is to hope that the next WCCES Congress in Mexico in 2019 will continue the good work.

Eliška Walterová Charles University, Faculty of Education Institute for Research and Development of Education eliska.walterova@pedf.cuni.cz 